\title{
MATE CHOICE IN THE GALILEE ST. PETER'S FISH, SAROTHERODON GALILAEUS
}

\author{
by
}

\begin{abstract}
ALBERT F.H. ROS, ILJA ZEILSTRA and RUI F. OLIVEIRA ${ }^{1)}$
(Unidade de Investigação em Eco-Etologia, Instituto Superior de Psicologia Aplicada, Rua Jardim do Tabaco 34, 1149-041, Lisboa, Portugal)
\end{abstract}

(Acc. 7-VIII-2003)

\begin{abstract}
Summary
This study reveals the correlation between operational sex ratio (OSR), body characteristics and pairing in one-year-old reproductively active St. Peter's fish, Sarotherodon galilaeus, a mouth brooding tilapia that shows a wide variety in mating strategies including uni- $v s$ biparental brood care, and monogamy $v s$ polygamy. In this study individually marked fish were exposed to different OSR regimes: male-biased, balanced, and female-biased. Larger individuals formed a pair more rapidly than smaller ones. A bias in the OSR caused a longer delay in pairing for individuals of the more abundant sex. The same patterns were found in males and females, supporting the theory that assortative mating patterns emerge due to both male and female choice. Furthermore, we found that pairs that spawned during the experiment were more closely matched in body size than pairs that were not successful in spawning, suggesting that size assortative mating has benefits for reproductive success in $S$. galilaeus.
\end{abstract}

1) The authors acknowledge the support of Prof. Dr. Lev Fishelson (Tel Aviv University, Israel), without whom this project would not have been possible. The authors also thank Dr. Noam Werner (Tel Aviv University, Israel) and Dr. Tamir Ezer and co-workers at the Experimental Station for Aquaculture (Dept. of Fisheries, Israel), for making facilities available, assistance in obtaining and maintaining fish, and the pleasant working environment. The research described here is part of a research grant awarded to RFO by the Portuguese Foundation for Science and Technology (FCT, project PRAXIS/P/BIA/10251/1998). AFHR was supported by a post-doctoral fellowship within the scope of this grant. RFO's research is supported by the Plurianual Program of FCT (R\&D Unit 331/94) and initial visits to Lake Kinnereth to develop this project were funded by the Israeli Embassy in Lisbon. We thank Dr. Ton Groothuis (University of Groningen) for making it possible for AFHR and IZ to participate in the research project. The 'Stichting Groninger Universiteitsfonds' and the 'Marco Polo Fonds' funded travels of IZ between the Netherlands, Israel and Portugal. We thank Anahita Kazem and two anonymous referees for improving the manuscript. 


\section{Introduction}

Spending time in searching for the best partner (i.e. choosiness), has both direct and indirect reproductive benefits. However, individuals that are more choosy run the risk of losing reproductive opportunities since the pool of potential partners gets smaller as pair formation progresses. Consequentially, when the sex ratio of animals available for reproduction in a population is skewed, choosiness is more costly for the more abundant sex than for the less abundant sex (e.g. Balshine-Earn, 1996). Therefore, the most abundant sex, often the male, is expected to be less choosy, and to have a higher propensity to become polygamous.

In many teleost species, mate search time is surprisingly short which makes research on factors influencing mate choice difficult (e.g. Baerends, 1984; Alcock, 1993). Body size is expected to play an important role in mate choice because larger males are more successful in establishing and defending high quality territories or spawning areas, and larger females have higher reproductive potential and may also help in territorial defence (Côté \& Hunte, 1989; Magnhagen \& Kvarnemo, 1989; Andersson, 1994; BalshineEarn, 1996). Accordingly, in binary choice tests, both males and females have been shown to prefer larger partners over smaller ones (Balshine-Earn, 1996; Beeching \& Hopp, 1999) and the predicted resulting assortative mating for body size has been detected in many species of teleost fishes (e.g. McKaye, 1986). Nevertheless, individual variation in assortative mating is high, indicating constraints in finding the optimal partner or in relative body size assessment (McKaye, 1986; Beeching \& Hopp, 1999).

Due to the pressure for pairing rapidly, pairs might be formed even before both partners are in reproductive state. After pair-bonds are established a period exists in which pairs stay together and show synchronous courtship behaviour before they reproduce (e.g. Baerends, 1984). In this period, synchronization of the male's and female's reproductive physiology takes place, but also partners might try to manipulate each others reproductive behaviour and physiology (Kobayashi et al., 2002; Wachtmeister, 2001).

Sarotherodon galilaeus (Cichlidae) is a monomorphic species that forms temporary pair-bonds and in which both sexes often participate in territorial behaviour and parental care (Schwanck \& Rana, 1991; Balshine-Earn, 1997). The mating behaviour of this species shows great variation between individuals and in time. After spawning, males and females may incubate 
the eggs and fry in their mouths or may refuse brooding (Balshine-Earn, 1997; Fishelson \& Hilzerman, 2002). Furthermore, males may switch partners after spawning or may stay with their partners for subsequent spawnings (Fishelson \& Hilzerman, 2002). Evolutionary modelling has shown that the operational sex ratio (OSR), i.e. partner availability, may play an important role in the plasticity in mating styles described above (Balshine-Earn \& Earn, 1997). In this study the interaction between OSR, body size, secondary sex characters and pairing in $S$. galilaeus were investigated.

\section{Methods}

\section{Animals and housing conditions}

The experiment was conducted at the Experimental Station for Aquaculture at Lake Kinnereth, Israel (Min. of Agriculture, Dept. of Fisheries). One hundred and twenty seven males and 125 females of Sarotherodon galilaeus were used in this study. All individuals were one year old. Fish from this station were selected in order to standardize age and life histories of the experimental animals. Moreover, long term stocking of Lake Kinnereth with commercially bred $S$. galilaeus has likely replaced most of the natural population (Ben-Tuvia et al., 1992). The experiment was conducted from May to June 1999. Three indoor concrete ponds measuring $6 \times 2 \mathrm{~m}$, received natural light entering through a row of windows $(40 \mathrm{~cm}$ high) located 1.3 meter above the ponds and through transparent capping (approx. $14: 10 \mathrm{~L}: \mathrm{D}$ cycle). The ponds had a deeper part with a water level of $40 \mathrm{~cm}$ deep $\left(2 \mathrm{~m}^{2}\right)$, and a shallow part that sloped from a water level of $30 \mathrm{~cm}$ to $20 \mathrm{~cm}$ deep. Extra structures (2 tubes and 3 flat stones) were provided on the bottom of the ponds for the fish to use as landmarks for territory establishment. Water in the ponds was continuously aerated and was refreshed by an inlet of water from the lake. The temperature of the water fluctuated between 24 and $29^{\circ} \mathrm{C}$, which reflects the natural variation of water temperature in Lake Kinnereth at this time of year. Fish were fed every two days with floating pellets (about 20 gram per kilogram of fish; Zemach, Israel). Additionally the fish foraged on algae growing in the ponds.

\section{Experimental design and procedures}

From field observations (Ros pers. obs.) we estimated that pairs defended territories of approximately $1 \mathrm{~m}^{2}$. To allow enough space for all pairs to establish breeding territories, 21 animals were placed in each pond (maximum 10 pairs per $12 \mathrm{~m}^{2}$ ). Three ponds were alternatively assigned to one of the three OSR groups: (1) a male-biased OSR group, which had twice as many males as females; (2) a control group, which had a balanced OSR; (3) a female-biased OSR group, which had twice as many females as males (for actual OSRs see below). Four replicates were obtained for each experimental treatment, comprising twelve experimental trials in total. Fish were acclimated to the indoor ponds for one week before the start of the experiment. At the start of each experimental trial the sex of the fish was determined by inspection of the shape of the genital papilla (females have a wide T-shaped slit and males have a single circular orifice, Balshine-Earn, 1996), and by applying a light pressure to the 


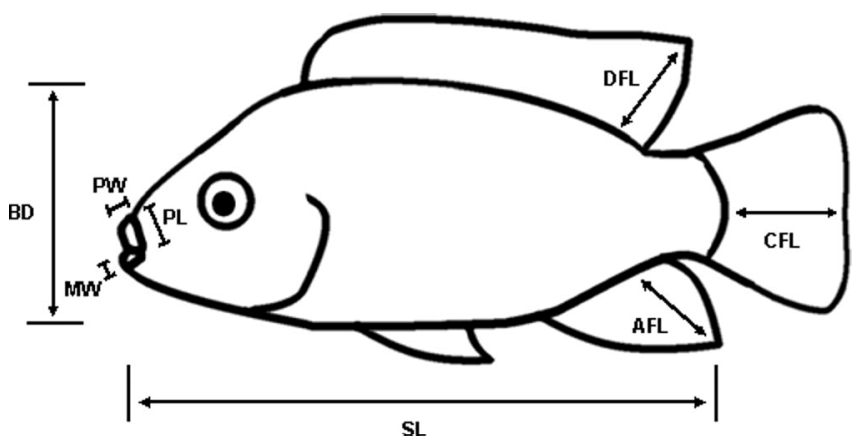

Fig. 1. Morphological measurements: $\mathrm{SL}=$ standard length: anterior edge of the upper lip to base of the caudal fin; $\mathrm{BD}=$ body depth: base of the ventral fins to top of the dorsal muscle; $\mathrm{CFL}=$ caudal fin length: length from base of the caudal fin to tip of the middle rays of the caudal fin; DFH = dorsal fin height: length of the largest fin ray of the dorsal fin, AFH = anal fin height: length of the largest fin ray of the anal fin; PL = premaxilla length: anterior edge of the upper lip to posterior edge of the jaw; $\mathrm{PW}=$ premaxilla width: maximum width of the upper lip; MW = mandible width: maximum width of the lower lip.

abdomen, which in males generally causes the release of urine whereas females almost never released urine. Each fish was weighed and marked with an individual combination of plastic colour beads $(\varnothing=4.5 \mathrm{~mm}$ ) on a fishing line (Spécial Marine, super soft, $\varnothing=0.2 \mathrm{~mm}$ ) attached to the dorsal muscle.

At the end of each experimental trial all males and females were caught and sacrificed using an overdose of anaesthetic (MS-222, tricaine methasulfonate, Sigma). To investigate the allometric relationships between potential secondary sex characters and body size the morphometric measurements described in Fig. 1 were taken (to the nearest $0.1 \mathrm{~mm}$ ) using callipers. Fish mass was measured (to the nearest $0.1 \mathrm{~g}$ ) using an electronic balance. The sex of the individual was confirmed by direct inspection of the gonads after dissection of the abdominal cavity and revealed that eight out of 252 fish were incorrectly sexed. The resulting OSRs in the ponds were on average 2.23:1 for the male-biased group, 1.15:1 for the control group, and $1: 2.5$ for the female-biased group.

\section{Behavioural observations}

Observations of all males and females in the ponds were carried out daily (average observation time: $2 \mathrm{~h}$ per pond per day) for the 14 days of the experiment. During these observations we recorded all occurrences in which individuals were courting each other or defending a territory together, the occurrence of spawning, and whether or not the male or female picked up eggs for mouth brooding.

The following measures were computed

Sexual dimorphism: To assess sexual dimorphism, the degree of overlap between the range of values recorded in each sex was calculated for each morphological variable. To calculate this score: (1) the highest value of the range of values that was shared between males and 
females was subtracted from the lowest value of this range; (2) this value was divided by the difference between the highest and the lowest value of the combined range of values in males and females; (3) the resulting value was multiplied by 100 to express the score as a percentage. In the event that the range of values for one sex fell entirely within the range of values for the other sex, a score of $100 \%$ would be given. The lower the score of a given variable the better it discriminates males from females. Ranges for the two sexes were strongly overlapping, as expected for a monomorphic species. To exclude outliers, the range encompassing $90 \%$ of the data was used to calculate the score.

Pairing interval: Pair formation was very conspicuous and was therefore selected to assess the experimental effect of OSR manipulation upon mate choice. The first day from which two animals were seen together for at least two days, and in which they were courting each other and were defending a territory together, was defined as the day of pairing. The pairing interval was calculated as the interval between the start of the experiment and the day of pairing. If animals had several partners during the experiment only the date of the first pairing was used to calculate the pairing interval. Time to spawning was not used as an additional measure of mate choice because many pairs did not spawn within the 16 day period of the trials and because spawning could be overlooked.

Territory quality index: The fish preferred to settle in both the deepest areas of the ponds and those furthest away from the observation walkway. To have a measure for the quality of the territory where animals settled, we calculated an index based on these apparent preferences of the fish. The shallow part of the pool $\left(6 \mathrm{~m}^{2}\right.$, about $20 \mathrm{~cm}$ deep) was given the lowest score of 1 , the part of the pool that was intermediate in depth $\left(4 \mathrm{~m}^{2}\right.$, about $30 \mathrm{~cm}$ deep $)$ was given a score of 2 , and the deepest part of the pool $\left(2 \mathrm{~m}^{2}\right.$, about $40 \mathrm{~cm}$ deep) was given a score of 3 . These scores were then added to a score of: 1 in case the territory was situated in the half of the pond that was closest to the walkway $\left(6 \mathrm{~m}^{2}\right), 2$ if the territory was situated further toward the back of the pond $\left(3 \mathrm{~m}^{2}\right)$, and 3 if the territory was situated in the preferred back part of the pond $\left(3 \mathrm{~m}^{2}\right)$. This produced an index which varied between 2 and 6 .

Body condition: Body mass at the start of the experiment divided by standard length (SL) to the 3rd power.

Pair matching: The degree of within-pair matching for body size was expressed as the absolute value of the difference between partners' relative body size, where an individual's relative body size was computed as their SL minus the average SL for their sex [abs(male SL-female SL-(avg(male SL)-avg(female SL))].

\section{Statistical tests}

To make sure that all animals in our dataset were sexually active we only used data from animals which paired. Eight out of the 100 paired males and four out of the 108 paired females formed homosexual pair bonds. These individuals were omitted from the current dataset. Thus the final sample sizes were: 92 males and 104 females.

For each of the experimental trials the average pairing interval was calculated for individuals that were larger than the median standard length within the trial and for those that were smaller than the median standard length within that trial. This resulted in a set of 12 independent data points for small and for large males and females. To test the relationship between partner availability and pairing interval we computed an Ancova with body size as 
repeated measurement ( 2 levels: large $v s$ small), sex as factor (2 levels) and partner availability as covariate, where partner availability was equivalent to the OSR for females, and to the inverse of the OSR for males.

To correct for differences in measurements between trials we standardized all data per trial to a mean of 0 with standard deviation of 1 . This yielded variables which had distributions that were not significantly different from the normal distribution. $p$-values were based on two-tailed tests and alpha was set to 0.05 . Bonferroni corrections were used to control for the inflation of alpha due to multiple testing.

\section{Results}

\section{Sexual dimorphism}

Paired males were on average $4.5 \%$ larger in body size than females (Table 1). When corrected for body size, males and females differed significantly in body depth, premaxilla length, the width of the mandible and premaxilla, and in dorsal fin height (Table 1). The ranges of body measurements in the two sexes were highly overlapping: the range encompassing $90 \%$ of the standard length values overlapped by $62 \%$ (Table 1), which confirms the monomorphic nature of this species. On average the overlap between male and female measurements (corrected for body size) was $80 \%$, with the highest degree of overlap for those characters that were least likely to be under sexual selection (e.g. body depth and caudal fin length, Table 1).

\section{Body size, morphological variables and pairing}

In both males and females standard length and body mass were highly negatively correlated with pairing interval, that is, larger individuals formed pairs more rapidly than smaller individuals (Fig. 2, males: SL, $r=-0.44$, $p<0.001 ; W, r=-0.33, p<0.01$; females: SL, $r=-0.34, p<0.001$; $W, r=-0.32, p<0.001)$. To detect whether sexually dimorphic characters in $S$. galilaeus were associated with pairing interval we controlled for allometric relationships with standard length using partial correlations. Only the width of the mandible in males exhibited a negative correlation with pairing interval [Partial correlation corrected for standard length ( $p$-values Bonferroni corrected): $\mathrm{MW}, r=-0.27, \mathrm{DF}=89, p<0.05$ (5 comparisons, 1 st rank), all other variables $|r|<0.21, \mathrm{DF}=89$, NS; in females: all variables $|r|<0.13, \mathrm{DF}=101, \mathrm{NS}]$. 


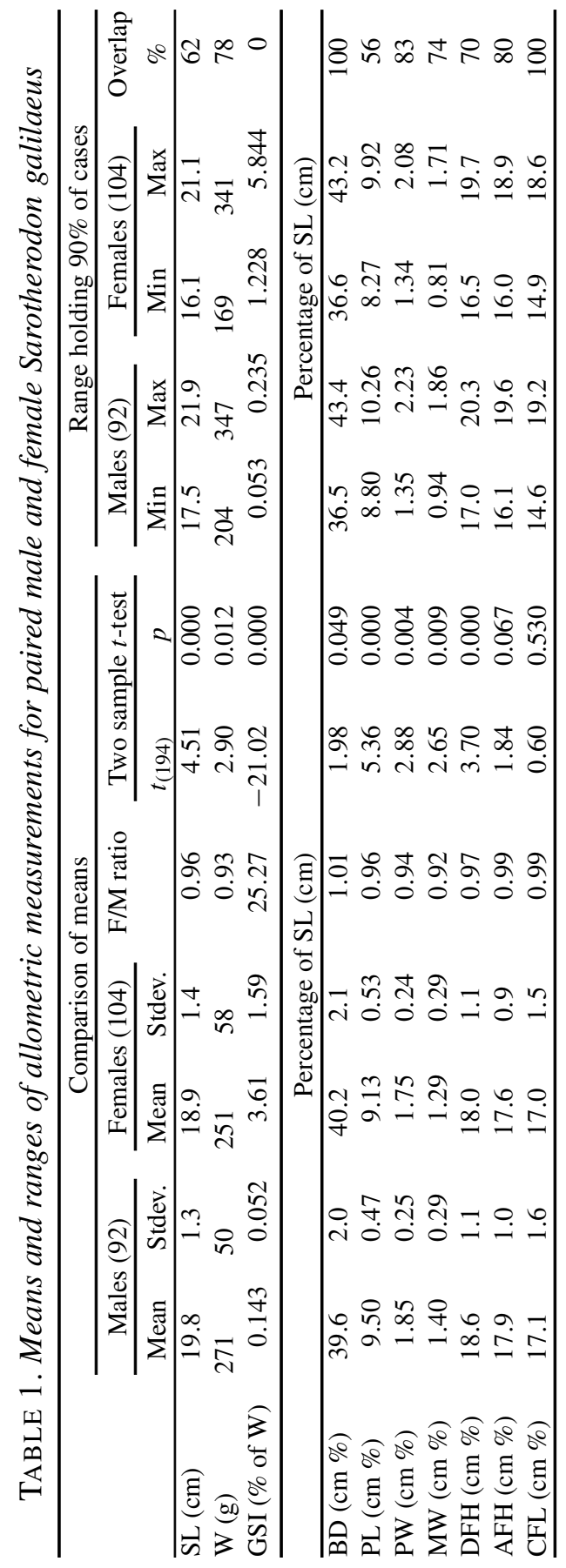




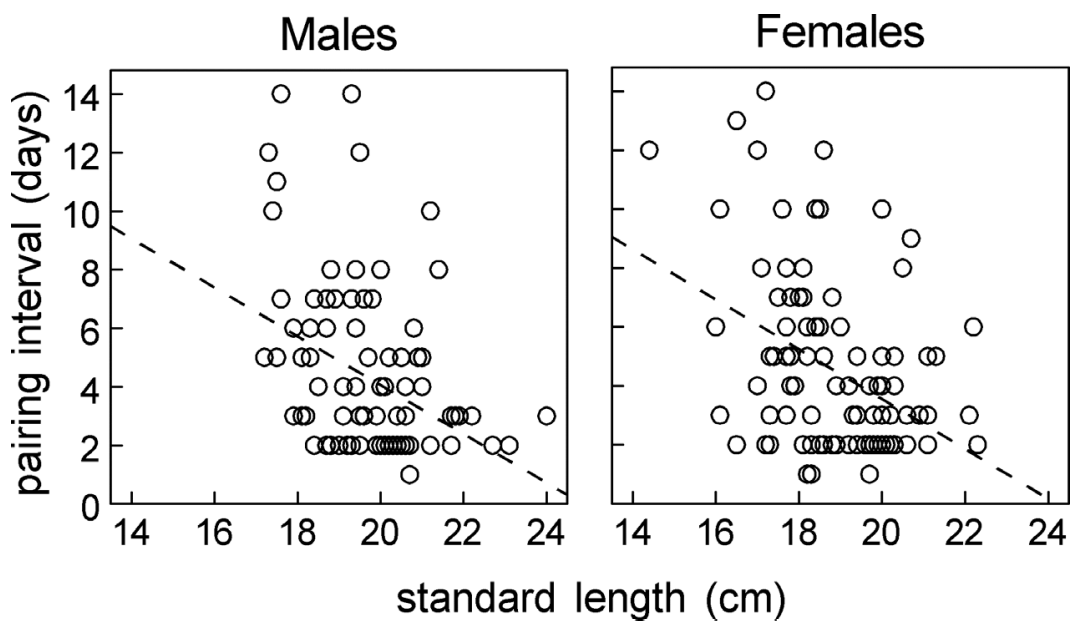

Fig. 2. Relationship between standard length and pairing interval for males and females.

Males with higher condition indices at the start of the experiment were slower in pairing and established lower quality territories than males with lower condition indices (males: $r=0.28, p<0.01 ; r=-0.28, p<0.01$, respectively; females: both $|r|<0.15$, NS).

\section{Territory quality and pairing}

Both paired and unpaired males competed with high levels of aggression for the deepest and furthest back areas of the ponds. Unpaired females were not territorial and hovered over the territories of males. As soon as females paired, they started to aggressively defend a territory together with their partner. During the mating phase males were on average more aggressive than their partners (Wilcoxon signed rank test, $U=55, N=29$ documented cases, $p<0.001$ ). Nevertheless, in $24 \%$ of these pairs the female was the most aggressive individual.

In both sexes pairing interval was negatively correlated, and body size and mass positively correlated, with the index for territory quality (males, pairing interval: $r=-0.36, p<0.001$; SL: $r=0.39, p<0.001 ; W: r=0.27$, $p<0.01$; females, pairing interval: $r=-0.37, p<0.001$; SL: $r=0.17$, $p=0.08 ; W: r=0.19, p<0.05)$. 


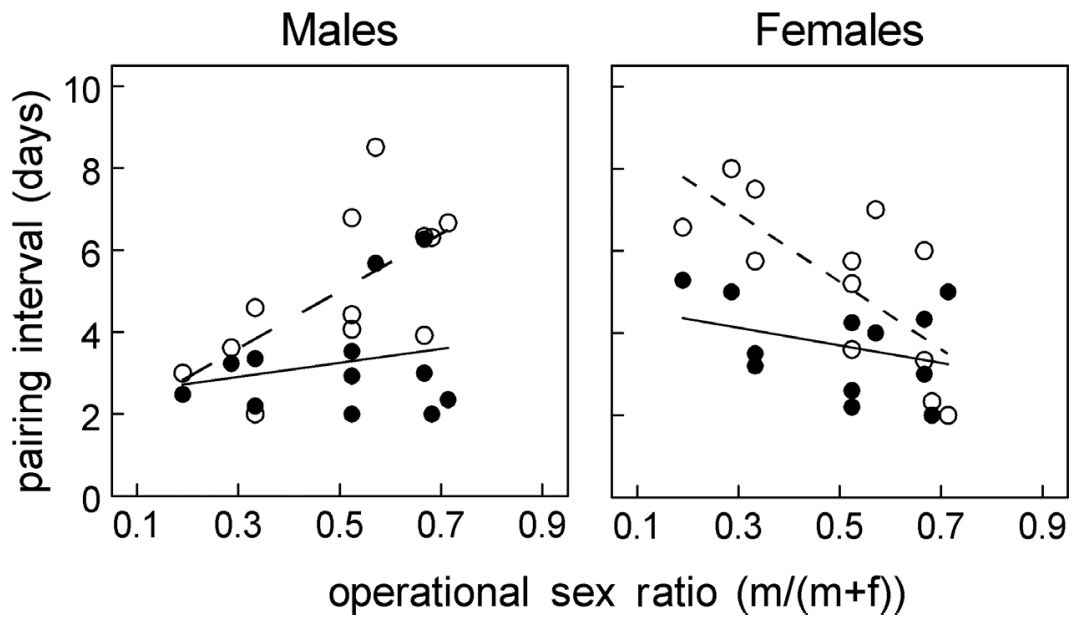

Fig. 3. Interaction between influence of body size and OSR upon pairing interval for males and females (days between the start of the experiment and formation of a pair). Filled symbols: individuals of large size; open symbols: individuals of small size. Pairwise averages were calculated per experimental trial ( $N=12$ trials).

\section{OSR and pairing}

An opposite trend for males and females was found in the relationship between pairing interval and OSR (Fig. 3). When availability of females decreased, the pairing interval for males increased whereas that for females decreased. As already shown above, being of larger standard length significantly shortened the pairing interval [Fig. 3; Ancova: $F_{(1,9)}=20.69$, $p<0.01]$. Males and females did not differ in pairing interval nor did the effect of standard length on pairing interval differ between males and females [Ancova: effect of sex, $F_{(1,9)}=0.61$, NS; interaction sex and SL, $\left.F_{(1,9)}=0.1, \mathrm{NS}\right]$. Partner availability was significantly negatively correlated with pairing interval [Ancova: $F_{(1,9)}=12.70, p<0.01$ ]. The interaction between partner availability and standard length was significant [Ancova: $\left.F_{(1,9)}=9.17, p<0.05\right]$. Post-hoc analyses showed that partner availability affected pairing interval in small individuals but not in large individuals [Fig. 3; Ancova: small individuals: $F_{(1,9)}=18.78, p<0.01$; large individuals: $\left.F_{(1,9)}=1.65, \mathrm{NS}\right]$. 


\section{Pairing and spawning success}

Of the 92 males that were paired 56 spawned (60.9\%). The pairing interval in males that subsequently spawned was significant shorter than that of males that did not spawn [ $t$-test: $\left.t_{(90)}=-2.99, p<0.01\right]$. Paired males that spawned were also significantly larger in body size than paired males that did not spawn [ $t$-test: $\left.t_{(90)}=2.33, p<0.05\right]$. Paired males that spawned lost more body mass during the experiment than paired males that did not spawn [ $t$-test: $\left.t_{(90)}=-2.05, p<0.05\right]$. Of the 104 females $(N$-value differs from that of males due to the occurrence of polygamy in both males and females) that were paired, 61 spawned $(58.7 \%)$. In contrast to males, paired females that spawned did not differ in either pairing interval or body size in comparison to paired females that did not spawn [ $t$-test: pairing interval: $t_{(102)}=-1.02$, NS; SL: $t_{(102)}=-0.95$, NS]. Paired females that spawned lost significantly more body mass than paired females that did not spawn [t-test: $\left.t_{(102)}=-5.14, p<0.001\right]$.

Of the 56 males that spawned, 27 males engaged in mouth brooding $(48 \%)$. These brooding males did not differ significantly from the males that did not brood in pairing interval, body mass loss, or in standard lenght $(t$ tests: $p>0.20)$. Of the 61 females that spawned, 49 females brooded $(80 \%)$. These brooding females lost more body mass than females that did not brood [ $t$-test: $\left.t_{(59)}=2.26, p=0.027\right]$. The percentage of females that spawned that engaged in brooding behaviour was significantly higher than that of males $\left(80 \%\right.$ of females, $N=61$ vs $48 \%$ of males, $N=56, \chi^{2}=13.2$, $p<0.001)$.

\section{Assortative mating}

A significant positive correlation was found between male and female standard length within a pair ( $r=0.39, p<0.001$, Fig. 4$)$. Thus, as expected assortative pairing for body size occurred. However a large variation existed in the relationship between male and female standard length. We tested the hypothesis that pairs that were 'less matched' in terms of standard length were less successful in terms of spawning than pairs that were 'closely matched'. In accordance with this hypothesis, body size differences were smaller within spawning pairs than within pairs that did not spawn $\left[t\right.$-test $t_{(92)}=2.78$, $p<0.01$, Fig. 5]. 


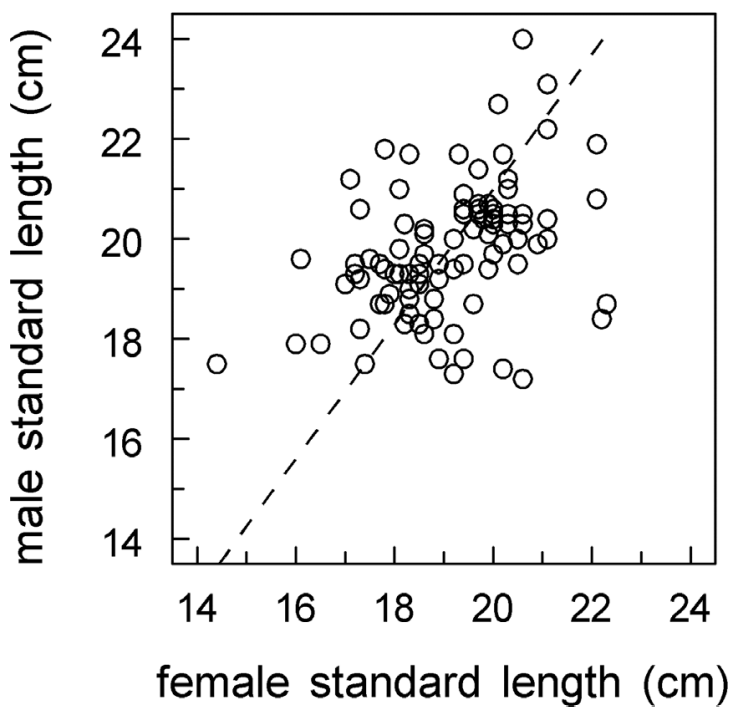

Fig. 4. Within-pair relationship between male and female standard length.

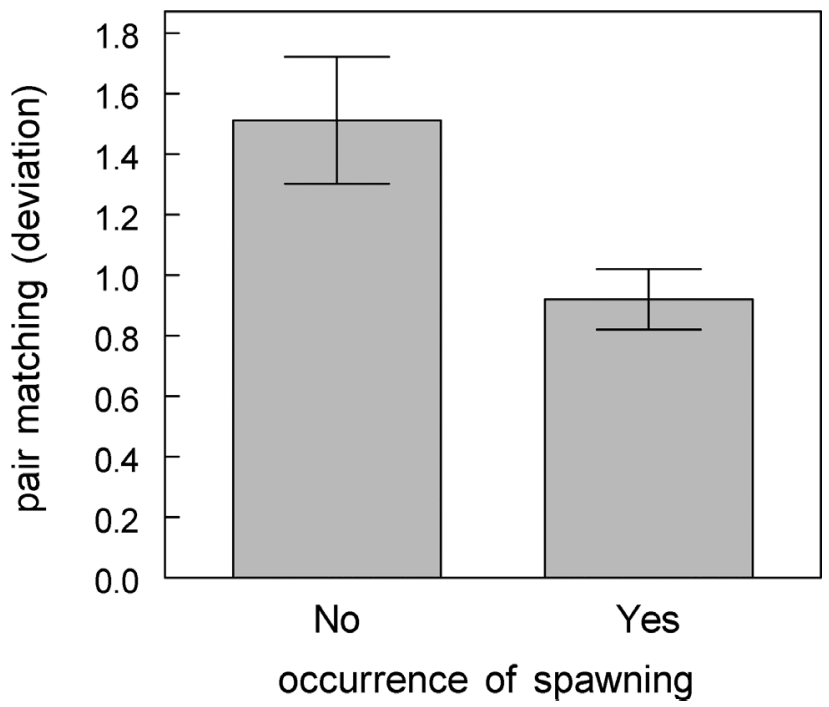

Fig. 5. Difference in the degree of matching of male and female body size, between pairs that spawned and pairs that did not spawn during the experiment. 


\section{Discussion}

\section{Sexual dimorphism}

The ranges of the allometric measurements corrected for body size of males and females were highly overlapping. The ratio of female to male body size (i.e. SL) was 0.95 , which is high in comparison with other cichlid species where females are usually much smaller than males (average 0.73: range 0.60-0.92, McKaye, 1986). Monomorphic traits are evolutionarily stable when similar selection pressures act on both sexes, or when there is an advantage for one or both sexes to conceal their sex (Burley, 1981). The latter might be relevant for Sarotherodon galilaeus, which forms monogamous pairs that spawn in close proximity (Fishelson, 1983). Concealing sex might decrease sexual competition, thereby allowing animals to put more resources into reproduction (Burley, 1981). This might however be at the cost of potential 'mistakes' in pairing, leading to homosexual pair bonds (Wingfield et al., 1982). In our experiment 8 males out of 100 paired males (8\%) formed a male-male pair and 4 out of 108 paired females (4\%) formed a female-female pair.

The main morphological difference between males and females was in the relative width of the upper lip of the mandible. This character was highly correlated with pairing interval. In a closely related species, Oreochromis mossambicus, this character is also sexually dimorphic (Oliveira \& Almada, 1995 ) and tends to be larger in more dominant males (Oliveira \& Almada, 1998) which have higher androgen levels (Oliveira et al., 1996). Thus, a possible alternative explanation for a positive correlation between sexually dimorphic characters and pairing interval is that males with more pronounced secondary sexual characters have higher androgen levels. High androgen levels facilitate male-male competition and courtship behaviour and males with higher androgen levels might therefore pair more rapidly than males with lower androgen levels (see also Couldridge \& Alexander, 2001).

\section{Choosiness for body size}

Balshine-Earn (1996) tested S. galilaeus in a binary choice test and showed that both males and females spent more time in front of the aquarium holding the larger of two individuals of the opposite sex. She concluded that both males and females were choosy for size or perhaps for morphological or 
behavioural variables which correlated with size. This study complements the results of Balshine-Earn (1996), by examining the actual pairing of free S. galilaeus in a semi-natural set-up. Of the morphological measurements, in both males and females standard length was the main factor explaining variation in the interval to pairing. The variation in pairing interval explained by body size was however rather low, being $19 \%$ in males and $11 \%$ in females. In summary these results indicate that the preference for large body size expressed in binary choice tests may be constrained by group factors in more natural situations.

In fish, body size is an important trait in male and female mate choice (Downhower et al., 1983; Keenleyside et al., 1985; Thompson, 1986; Bisazza \& Marconato, 1988; Hastings, 1988; Côté \& Hunte, 1989; Magnhagen \& Kvarnemo, 1989; Balshine-Earn, 1997; Howard et al., 1998; Beeching \& Hopp, 1999; Oliveira et al., 1999, 2000; Taborsky, 1999). BalshineEarn (1996) summarized the possible benefits for a preference for larger mates as follows: (1) large mates are likely to have more energetic resources than small mates and therefore be able to invest relatively more in raising the brood; (2) larger mates are older and may be better partners since they have already gained brooding experience; (3) larger mates are more successful in aggressive competition and thus provide better defence against predators; (4) in females fecundity correlates with female size (see also Schwanck \& Rana, 1991).

In this experiment all fish were one year old but nevertheless exhibit substantial variation in body size. Larger males were able to establish territories in the deeper and less exposed areas of the ponds. Such territories were preferred by pairs although defending them did not provide immediate benefits such as food resources, since $S$. galilaeus is a filter feeder and feeding is reduced during the reproductive season (Trewavas, 1983). It has been postulated that defending a territory together with a partner may play an important role in suppressing aggressive behaviour and synchronising the reproductive cycle of both partners (Baerends, 1984).

As a consequence of male and female preferences for larger body size, assortative pairing was expected. We found a positive though weak correlation between male and female size in our experiments. Size-assortative mating is a general phenomenon in cichlid fish (e.g. McKaye, 1986; Beeching \& Hopp, 1999). It has been proposed in a bird species that partners which are better 
matched in terms of body characteristics (or in other terms 'more compatible'), might have higher chances of reproducing successfully (see Coulson \& Thomas, 1983). We checked this in our data by calculating the absolute difference between male and female standard length. In agreement with the 'compatibility hypothesis' pairs that spawned were relatively better matched in body size than pairs that did not spawn during the experiment.

\section{OSR and mate choice}

Experimental manipulation of OSRs in the ponds showed that the time before pairing was greater when fewer partners were available. This correlation was symmetrical for males and females, indicating both male and female mate choice. We found that the relationship between OSR and pairing was different for relatively larger and smaller individuals. The time before pairing was independent of OSR regime for relatively large animals, which were preferred as partners. However, relatively smaller individuals mated as rapidly as large ones when partner availability was high, whereas it took small animals more time to mate than large ones when partner availability was low. Hence choosiness for size decreased when partner availability was low. A relationship between OSR and choosiness has already been described among teleosts for pipefish, gobies and guppies (Berglund, 1994; Kvarnemo et al., 1995, Jirotkul, 1999). Choosing the best available partner should increase the quality of reproduction, but higher costs have been proposed in terms of the time spent searching and sampling mates (see Real, 1991).

In conclusion, the data support a trade-off between the degree of choosiness and the loss of pairing opportunities, depending on the OSR in the population.

\section{References}

Alcock, J. (1993). Animal behavior. — Sinauer Associates, Sunderland, MA. Andersson, M.B. (1994). Sexual selection. - Princeton University Press, Princeton.

Baerends, G.P. (1984). The organization of the pre-spawning behaviour in the cichlid fish Aequidens portalegrensis (Hensel). — Neth. J. Zool. 34, p. 233-366.

Balshine-Earn, S. (1996). Reproductive rates, operational sex ratios and mate choice in St. Peter's fish. - Behav. Ecol. Sociobiol. 39, p. 107-116.

- - (1997). The benefits of uniparental versus biparental mouth brooding in Galilee St. Peter's fish. - J. Fish Biol. 50, p. 371-381. 
— — \& Earn, D.J.D. (1997). An evolutionary model of parental care in St. Peter's fish. — J. theor. Biol. 184, p. 423-431.

Beeching, S.C. \& Hopp, A.B. (1999). Male mate preference and size-assortative pairing in the convict cichlid. - J. Fish Biol. 55, p. 1001-1008.

Ben-Tuvia, A., Davidoff, E.B., Shapiro, J. \& Shefler, D. (1992). Biology and management of Lake Kinnereth fisheries. - Israel J. Aquac. 44, p. 48-65.

Berglund, A. (1994). The operational sex ratio influences choosiness in a pipefish. - Behav. Ecol. 5, p. 254-258.

Bisazza, A. \& Marconato, A. (1988). Female mate choice male-male competition and parental care in the river bullhead Cottus-gobio L. Pisces, Cottidae. - Anim. Behav. 36, p. 1352-1360.

Burley, N. (1981). The evolution of sexual indistinguishability. - In: Natural selection and social behavior: recent research and new theory (R.D. Alexander and D.W. Tinkle, eds). Chiron Press, New York.

Côté, I.M. \& Hunte, W. (1989). Male and female mate choice in the redlip blenny: why bigger is better. - Anim. Behav. 38, p. 78-88.

Couldridge, V.C.K. \& Alexander, G.J. (2001). Does the time spent near a male predict female mate choice in a Malawian cichlid? - J. Fish Biol. 59, p. 667-672.

Coulson, J.C. \& Thomas, C.S. (1983). Mate choice in the kittiwake gull. — In: Mate choice (P. Bateson, ed.). Cambridge University Press, Cambridge, p. 361-376.

Downhower, J.F., Brown, L., Pederson, R. \& Staples, G. (1983). Sexual selection and sexual dimorphism in mottled sculpins. - Evolution 37, p. 96-103.

Fishelson, L. (1983). Social behaviour of adult tilapia fish in captivity (Israel). — In: Proceedings of the International Symposium on Tilapia in Aquaculture (L. Fishelson \& Z. Yaron, eds). Tel Aviv University Press, Tel Aviv, p. 48-58.

— — \& Hilzerman, F. (2002). Flexibility in reproductive styles of male St. Peter's tilapia, Sarotherodon galilaeus (Cichlidae). - Environ. Biol. Fishes 63, p. 173-182.

Hastings, P.A. (1988). Female choice and male reproductive success in the angel blenny Coralliozetus angelica Teleostei Chaenopsidae. - Anim. Behav. 36, p. 115-124.

Howard, R.D., Martens, R.S., Innis, S.A., Drnevich, J.M. \& Hale, J. (1998). Mate choice and mate competition influence male body size in Japanese medaka. - Anim. Behav. 55, p. 1151-1163.

Jirotkul, M. (1999). Operational sex ratio influences female preference and male-male competition in guppies. - Anim. Behav. 58, p. 287-294.

Keenleyside, M.H.A., Rangeley, R.W. \& Kuppers, B.U. (1985). Female mate choice and male parental defence behaviour in the cichlid fish Cichlasoma nigrofasciatum. - Can. J. Zool. 63, p. 2489-2493.

Kobayashi, M., Sorensen, P.W. \& Stacey, N.E. (2002). Hormonal and pheromonal control of spawning behavior in the goldfish. - Fish Physiol. Biochem. 26, p. 71-84.

Kvarnemo, L., Forsgren, E. \& Magnhagen, C. (1995). Effects of sex ratio on intra- and intersexual behaviour in sand gobies. - Anim. Behav. 50, p. 1455-1461.

Magnhagen, C. \& Kvarnemo, L. (1989). Big is better: the importance of size for reproductive success in male Pomatoschistus minutus (Pallas) (Pisces, Gobiidae). — J. Fish Biol. 35, p. 755-563.

McKaye, K.R. (1986). Mate choice and size assortative pairing by the cichlid fishes of Lake Jiloá, Nicaragua. — The Fisheries Soc. British Isles 29, p. 136-161. 
Oliveira, R.F. \& Almada, V.C. (1995). Sexual dimorphism and allometry of external morphology in Oreochromis mossambicus. — J. Fish Biol. 46, p. 1055-1064.

— — \& - (1998). Androgenization of dominant males in a cichlid fish: androgens mediate the social modulation of sexually dimorphic traits. - Ethology 104, p. 841858.

— —, — — \& Canário, A.V.M. (1996). Social modulation of sex steroid concentrations in the urine of male cichlid fish Oreochromis mossambicus. — Horm. Behav. 30, p. 2-12.

_ _, _ —, Forsgren, E. \& Gonçalves, E.J. (1999). Temporal variation in male traits, nesting aggregations and mating success in the peacock blenny. - J. Fish Biol. 54, p. 499-512.

— - Miranda, J.A., Carvalho, N., Gonçalves, E.J., Grober, M.S. \& Santos, R.S. (2000). Male mating success in the Azorean rock-pool blenny: the effects of body size, male behaviour and nest characteristics. - J. Fish Biol. 57, p. 1416-1428.

Real, L.A. (1991). Search theory and mate choice. II. Mutual interaction assortative mating, and equilibrium variation in male and female fitness. - Am. Nat. 138, p. 901-917.

Schwank, E. \& Rana, K. (1991). Male-female parental roles in Sarotherodon galilaeus (Pisces: Cichlidae). - Ethology 89, p. 229-243.

Taborsky, M. (1999). Alternative male reproductive tactics in fish. - In: Behaviour and conservation of littoral fishes (V.C. Almada, R.F. Oliveira \& E.J. Gonçalves, eds). ISPA, Printipo Lisboa, Lisbon, p. 301-349.

Thompson, S. (1986). Male spawning success and female choice in the mottled triplefin, Forsterygion varium (Pisces: Tripterygiidae). - Anim. Behav. 34, p. 580-589.

Trewavas, E. (1983). Tilapiine fishes of the genera Sarotherodon, Oreochromis and Danakilia. - British Mus. Nat. Hist., London.

Wachtmeister, C.A. (2001). Display in monogamous pairs: a review of empirical data and evolutionary explanations. - Anim. Behav. 61, p. 861-868.

Wingfield, J.C., Newman, A.L., Hunt, G.L. \& Farner, D.S. (1982). Endocrine aspects of female-female pairing in the Western gull (Larus occidentalis wymani). - Anim. Behav. 30, p. 9-22. 